\title{
Learning Styles of Students: A Case Study
}

\author{
Prashant A. Athavale ${ }^{1}$, H. D. Kattimani ${ }^{1}$, Dr. P. S. Puttaswamy ${ }^{2}$ \\ ${ }^{1}$ Department of Electrical \& Electronics, BMS Institute of Technology and Management, Bengaluru - 560064 \\ ${ }^{2}$ Department of Electrical \& Electronics, PES College of Engineering, Mandya \\ ${ }^{1}$ prashanth@bmsit.in \\ ${ }^{1}$ hdk.bms@gmail.com
}

\begin{abstract}
In this paper, we present a case study of understanding and classifying the learning styles of undergraduate engineering students. The distribution in each of the four dimensions of learning styles is determined. Based on the results, the students were informed about their respective learning styles and the ways in which they could improve the performance was also intimated.
\end{abstract}

Keywords: Learning Styles, Active Learners, Sensing Learners

Prashant A. Athavale ${ }^{1}$

${ }^{1}$ Department of Electrical \& Electronics, BMS Institute of Technology and Management, Bengaluru - 560064 ${ }^{1}$ prashanth@bmsit.in
The most valuable resource that all teachers have is each other. Without collaboration our growth is limited to our own perspectives. - Robert John Meehan

\section{Introduction}

As faculty in esteemed Institutes, we have come across a wide variety of students over the past years. These students, who are admitted to the 4 year undergraduate engineering education, have different socio-economic backgrounds. The seat allotment in the professional courses is done through a common Board, based on the merit in previous examinations at the $10+2$ level, along with the score in an Entrance exam conducted. The students would come from both rural and urban parts. The language for communication being various vernaculars found in India, along with English. Each of these students has different reasons for choosing our Programme at BMS Institute of Technology and Management, or elsewhere, guided by their respective family members, friends, teachers and/or other acquaintances. This is a cause for the 'variety' in terms of their knowledge levels when they enter the portals of our Institute.

But when we are delivering a course to such a set of students (60 to 70 students in a section), we always find a difference in the learning ability among that set. The students learning ability will decide the performance in all the areas in the course: the general attention and participation in the class-room teaching-learning process, conducting experiments in laboratory, record writing, interaction with the faculty and instructors, participation in various co-curricular activities in the programme, and finally the performance in internal assessment tests and semester end examinations. Here the instructors approach towards teaching has not been considered. Some of the instructors may give only lecture, some a demonstration in the class, focusing on only certain aspects of the entire curriculum.

We planned to classify the students based on their learning ability. The intention was to reach out to individual student, and bring him on par with others. But such a task would require interaction with students to know them in a better way with respect to the way they learn. We came across a wide array of methods and tools to classify them based on their learning styles. The learning style might be different, but the learner is expected to, in due course of time, learn the contents of a course. 
In our view, the learning of the contents of a course is to process, understand and take in the information, and be able to retrieve it. As applied to the engineering courses, the learner must be able to analyse and also interpret the information available to him in the form of diagrams, wave forms, or a table of data.

In this paper, we discuss the application of one such instrument known as Index of Learning Styles (ILS), and the student is made aware of the same, so that he improves attitude towards learning, resulting in academic achievement through scores and improves creativity.

\section{About Index of Learning Styles}

This is a questionnaire for determining the learning styles of students, developed by Richard M. Felder and Linda Silverman across four dimension of learning viz. ActiveReflective, Sensing-Intuitive, Visual-Verbal, and Sequential - Global. These dimensions were already a part of other such efforts made by educational researchers to classify the learning styles of the students. This questionnaire is also adapted in an online format and is made available. This has been used by various educators to determine the type of learners they have, and have been successful in improving the performance of the students.

\section{Learning Styles: An Overview}

Here is a brief description of the different dimension of learning as mentioned previously. It may look like there is some overlap between the categories presented here, but on careful observation each seems to be different. Also, the learners might act as belonging to either class but, their tendencies are more strongly oriented to one side. This is classified in ILS as strong, moderate, and mild. As mentioned elsewhere, good learners learn in any way.

\section{A. Active and Reflective Learners}

Both of the categories of learners process the information available to them in the external world in the form of instructions by a person / manual, diagrams, waveforms etc. and conclude about it in their mind, which has been termed as internal world. The term 'active' is for learners who want to try out things by 'active experimentation'. These learners will learn effectively when he is able to experiment in the laboratory or try it out on a simulator. The active learners will discuss the concepts with others and try to arrive at the core of the problem based on the instructions received, whereas reflective learners will be more introvert and try to think through the concepts. He will observe and think about all the possibilities before conducting experiments. Some studies have indicated that engineers are more active learners than reflective. As is evident, if the delivery of content is through only lectures, then the active learners tend to get bored, and may dislike the contents. On the same lines, the reflective learners will fail to keep up with the rest if content delivery is only hands on. Also, the active learners will gather around peer group and experiment, where as the other class will be with relatively small group or mostly alone.

\section{B. Sensing and Intuitive learners}

The 'sensors' are more oriented towards learning facts, whereas 'intuitive' learners who are better at understanding the underlying principles and abstractions, prefer discovering new possibilities. The intuitive learners do not like courses which are having routine and predictable calculations and outcomes, like Power System Analysis, where as Programming and Network Synthesis will be welcomed.

\section{Visual and Verbal Learners}

As is evident from the names, 'verbal' learners tend to understand more from the written texts or spoken explanation, as against the 'visual' learners, who tend to understand by images, block-diagrams, or maps. The courses which are more of 'theory' are not a favourite course for visual learners, like Engineering Materials, or Entrepreneurship and Management Principles.

\section{Sequential and Global Learners}

Sequential learners tend to understand the concept in logical order. The outcome of each step is connected by them to finally arrive at the big picture. The 'global' learners, on the other hand understand the 'big picture' or the gist of the matter, and then try to figure out how individual steps worked. The details are not clearly known to global learners as they do not think sequentially.

\section{Data and Method of collecting the ILS from UG students:}

We collected the inputs from the students of Electrical and Electronics Engineering Department, of BMS Institute of Technology and Management, Bengaluru. The 59 students were of $3^{\text {rd }}$ semester (referred to as set 'A') and 57 students of $5^{\text {th }}$ semester (referred to as set ' $\mathrm{B}$ ') were given the forms on the opening day of the semester. The students were informed about the purpose of taking this data, and after the completion of the survey, they were handed out a description of the learning styles, which later found to be very useful to them. The total number of forms that we collected was, thus 116, and represented a considerable number to analyse and ponder over.

The following tables give the Report Form of ILS for the above said set of students. The numbers represent the same meaning as in the original work, with 1 and 3 score as fairly well balanced learners, 5 to 7 meaning moderate preference for a particular dimension and 9 or 11 meaning strong preference for one dimension.

Table 1. Percentage of students for the Active and Reflective learners category

\begin{tabular}{|c|c|c|c|c|}
\hline \multicolumn{5}{|c|}{ Set of Students: A } \\
\hline $\begin{array}{l}\frac{0}{\pi} \\
\tilde{U}\end{array}$ & : & 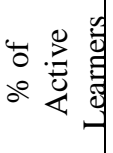 & 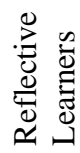 & 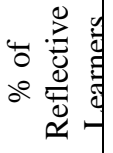 \\
\hline 1 & 10 & 16.9 & 10 & 16.9 \\
\hline 3 & 08 & 13.55 & 11 & 18.6 \\
\hline 5 & 04 & 6.77 & 08 & 13.5 \\
\hline
\end{tabular}




\begin{tabular}{|c|c|c|c|c|}
\hline 7 & 04 & 6.77 & 04 & 6.77 \\
\hline 9 & 00 & 00 & 00 & 00 \\
\hline 11 & 00 & 00 & 00 & 00 \\
\hline$\sum$ & 26 & 44.06 & 33 & 55.9 \\
\hline
\end{tabular}

Table 2. Percentage of students for the Sensing and Intuitive learners category

\begin{tabular}{|c|c|c|c|c|}
\hline \multicolumn{5}{|c|}{ Set of Students: A } \\
\hline$\underset{\tilde{U}}{\stackrel{0}{\tilde{J}}}$ & 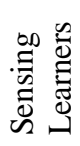 & 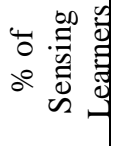 & 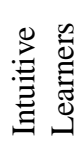 & 岁: 总 \\
\hline 1 & 10 & 16.9 & 14 & 23.7 \\
\hline 3 & 08 & 13.55 & 07 & 11.9 \\
\hline 5 & 03 & 5.08 & 07 & 11.9 \\
\hline 7 & 03 & 5.08 & 05 & 8.47 \\
\hline 9 & 00 & 00 & 01 & 1.67 \\
\hline 11 & 00 & 00 & 01 & 1.67 \\
\hline$\sum$ & 24 & 40.6 & 35 & 59.3 \\
\hline
\end{tabular}

Table 3. Percentage of students for the Visual and Verbal learners category

\begin{tabular}{|c|c|c|c|c|}
\hline \multicolumn{5}{|c|}{ Set of Students: A } \\
\hline $\begin{array}{l}\frac{0}{\tilde{U}} \\
\tilde{S}\end{array}$ & 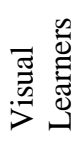 & 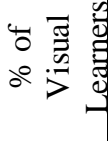 & 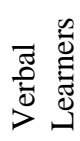 & 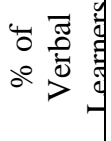 \\
\hline 1 & 11 & 18.64 & 05 & 8.47 \\
\hline 3 & 05 & 8.47 & 03 & 5.08 \\
\hline 5 & 14 & 23.72 & 03 & 5.08 \\
\hline 7 & 05 & 8.47 & 03 & 5.08 \\
\hline 9 & 08 & 13.55 & 00 & 00 \\
\hline 11 & 02 & 3.38 & 00 & 00 \\
\hline$\sum$ & 45 & 76.27 & 14 & 23.7 \\
\hline
\end{tabular}

Table 4. Percentage of students for the Sequential and Global learners category

\begin{tabular}{|c|c|c|c|c|}
\hline \multicolumn{5}{|c|}{ Set of Students: A } \\
\hline$\frac{\mathscr{U}}{\tilde{U}}$ & 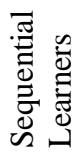 & 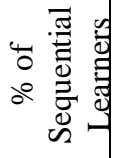 & 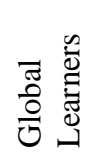 & 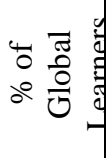 \\
\hline 1 & 16 & 27.11 & 10 & 16.9 \\
\hline 3 & 07 & 11.86 & 06 & 10.2 \\
\hline 5 & 12 & 20.33 & 00 & 00 \\
\hline 7 & 04 & 6.77 & 04 & 6.77 \\
\hline 9 & 00 & 00 & 00 & 00 \\
\hline
\end{tabular}

\begin{tabular}{|c|c|c|c|c|}
\hline 11 & 00 & 00 & 00 & 00 \\
\hline$\sum$ & 39 & 66.10 & 20 & 33.9 \\
\hline
\end{tabular}

Table 5. Percentage of students for the Active and Reflective learners category

\begin{tabular}{|c|c|c|c|c|}
\hline \multicolumn{5}{|c|}{ Set of Students: B } \\
\hline$\underset{\mathscr{U}}{\tilde{U}}$ & 总壳 & 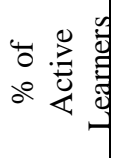 & 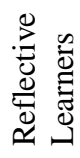 & 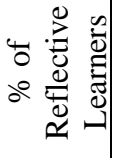 \\
\hline 1 & 10 & 17.54 & 11 & 19.3 \\
\hline 3 & 06 & 10.52 & 13 & 22.8 \\
\hline 5 & 05 & 8.77 & 06 & 10.52 \\
\hline 7 & 01 & 1.75 & 04 & 7.01 \\
\hline 9 & 00 & 00 & 01 & 1.75 \\
\hline 11 & 00 & 00 & 00 & 00 \\
\hline$\sum$ & 22 & 38.59 & 35 & 61.4 \\
\hline
\end{tabular}

Table 6. Percentage of students for the Sensing and Intuitive learners category Set of Students: B

\begin{tabular}{|c|c|c|c|c|}
\hline $\begin{array}{l}\frac{\mathscr{J}}{\tilde{J}} \\
\stackrel{w}{n}\end{array}$ & 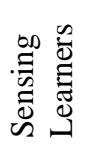 & 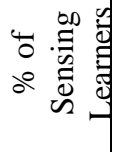 & 忐离 & 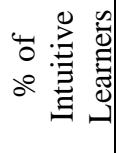 \\
\hline 1 & 10 & 17.54 & 08 & 14.03 \\
\hline 3 & 06 & 10.52 & 15 & 26.31 \\
\hline 5 & 03 & 5.26 & 04 & 7.01 \\
\hline 7 & 06 & 10.52 & 03 & 5.26 \\
\hline 9 & 01 & 1.75 & 01 & 1.75 \\
\hline 11 & 00 & 00 & 00 & 00 \\
\hline$\sum$ & 26 & 45.61 & 31 & 54.38 \\
\hline
\end{tabular}

Table 7. Percentage of students for the Visual and Verbal learners category

\begin{tabular}{|c|c|c|c|c|}
\hline \multicolumn{5}{|c|}{ Set of Students: B } \\
\hline $\begin{array}{l}\frac{\mathscr{J}}{\tilde{J}} \\
\tilde{n}\end{array}$ & 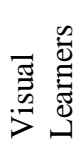 & 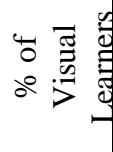 & 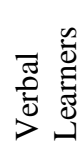 & 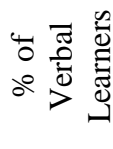 \\
\hline 1 & 07 & 12.28 & 01 & 1.75 \\
\hline 3 & 06 & 10.52 & 05 & 8.77 \\
\hline 5 & 13 & 22.8 & 00 & 00 \\
\hline 7 & 18 & 31.57 & 00 & 00 \\
\hline 9 & 07 & 12.28 & 00 & 00 \\
\hline 11 & 00 & 00 & 00 & 00 \\
\hline
\end{tabular}




\begin{tabular}{|c|c|c|c|c|}
\hline$\sum$ & 51 & 89.47 & 06 & 10.52 \\
\hline \multicolumn{5}{|c|}{$\begin{array}{l}\text { Table } 8 . \text { Percentage of students for the } \\
\text { Sequential and Global learners } \\
\text { category }\end{array}$} \\
\hline \multicolumn{5}{|c|}{ Set of Students: B } \\
\hline $\begin{array}{l}\frac{0}{\tilde{J}} \\
\mathscr{n}\end{array}$ & 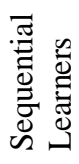 & 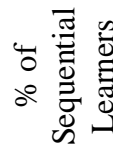 & 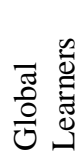 & 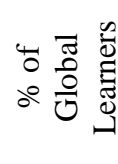 \\
\hline 1 & 17 & 29.82 & 12 & 21.1 \\
\hline 3 & 09 & 15.78 & 05 & 8.77 \\
\hline 5 & 06 & 10.52 & 02 & 3.5 \\
\hline 7 & 01 & 1.75 & 01 & 1.75 \\
\hline 9 & 03 & 5.26 & 00 & 00 \\
\hline 11 & 01 & 1.75 & 00 & 00 \\
\hline$\sum$ & 37 & 64.9 & 19 & 33.3 \\
\hline
\end{tabular}

Table 9. Consolidated distribution of learners across the above mentioned types. The total number of students will be 116 .

\begin{tabular}{|c|l|c|c|}
\hline $\begin{array}{c}\text { Sl. } \\
\text { No }\end{array}$ & \multicolumn{1}{|c|}{ Category } & $\begin{array}{c}\text { Total } \\
\text { Students }\end{array}$ & Percentage \\
\hline \multirow{2}{*}{1.} & Active Learners & 48 & 41.37 \\
\cline { 2 - 4 } & Reflective Learners & 68 & 58.62 \\
\hline \multirow{2}{*}{2.} & Sensing Learners & 50 & 43.10 \\
\cline { 2 - 4 } & Intuitive Learners & 66 & 56.89 \\
\hline \multirow{2}{*}{3.} & Visual Learners & 96 & 82.75 \\
\cline { 2 - 4 } & Verbal Learners & 20 & 17.24 \\
\hline \multirow{2}{*}{4.} & Sequential learners & 76 & 65.51 \\
\cline { 2 - 4 } & Global learners & 40 & 34.48 \\
\hline
\end{tabular}

\section{Results and Discussion:}

As mentioned in the above tables 1 to 9 , it can be observed that the students have a wide variety of learning styles. Based on the 4 dimensions mentioned in Felders' ILS questionnaire, we have obtained the specific numbers of students for each dimension and respective orientation. As per the ILS, a score on the scale having 1-3 is considered fairly well balanced on the respective dimensions. In this case study, 1 and 3 are given separate importance, and results are tabulated. And the same is true for 5-7 and 9-11 classes also.

A deviation as observed in Table 9 is that $59 \%$ of the total student strength who took up this survey, are Reflective Learners, as against the remaining $41 \%$ Active learners. This is not in accordance with the general perception about engineering students. Yet, this will not affect the quality of the graduates in any way. The percentage of Intuitive learners is around 57\%. This could be related to the requirement of graduates to work on interdisciplinary projects and in teams. The visual learners' category is the largest with $83 \%$ of students in it. It is important to understand that the courses taught in engineering programmes require visualization of concepts to arrive at a solution to a given problem. The remaining students will find it difficult to appreciate the contents in courses like Signals and Systems or Logic Design, where text or verbal information is minimal. Input and output are predominantly in mathematical equation form or in waveforms. These set Jêr of students might find the courses like Constitution and Civil Justice, Management and Entrepreneurship a bit easy to remember and retrieve the information. The next category of learning styles is sequential and $65.5 \%$ of the students are in this. There are courses like Design of Machines, which is predominantly a sequential application of the rules. The students who are in the 'global' category may find it difficult to fare well in such courses.

\section{Conclusions}

This and other materials were circulated among the students. The students find it beneficial to know about their learning style and understand the implications. Many queries of the students were answered in the subsequent days, after taking this survey. The students were also warned about the limitations of the same, and not to over interpret the outcomes. In future, we would like to correlate the data with the performance in the internal assessment test and external examination scores.

\section{Acknowledgement}

The authors are thankful to the Management and principal of BMS Institute of Technology and Management, Bengaluru, for providing an opportunity for carrying out this work.

\section{References:}

Are Learning Styles Invalid? (Hint: No!)

Richard M. Felder, North Carolina State University

Learning And Teaching Styles In Engineering Education , Engr. Education, 78(7), 674-681,1988

Understanding Student Differences: Richard M. Felder, Rebecca Brent, Journal of Engineering Education, 94(1), 57 $-72,2005$

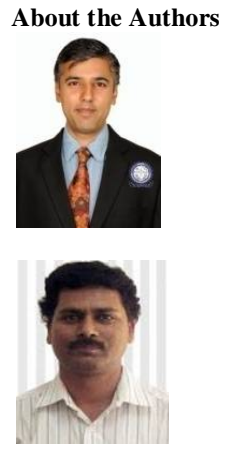

Prashant A. Athavale has obtained his Bachelor's Degree in Electrical and Electronics Engineering in 2003, and Masters Degree in Biomedical Signal Processing in 2008. His areas of interests are Signal Processing, Education research.

H. D. Kattimani received BE from Gulbarga University and MS( Electronics and Controls) from Birla Institute of technology, Pilani, Rajasthan. He is member of IEEE, ISTE and IEI. He is also a fellow of IETE Bengaluru region.

Dr. P. S. Puttaswamy is a Professor at PES College of Engineering, Mandya, with over 32 years of teaching and research experience. 